\title{
Characterization of a Planar Solid Oxide Cell Stack Operated at Elevated Pressure
}

\author{
Jensen, Søren Højgaard; Graves, Christopher R.; Chen, Ming; Hansen, J. B.; Sun, Xiufu
}

Published in:

Journal of The Electrochemical Society

Link to article, DOI:

10.1149/2.1171614jes

Publication date:

2016

Document Version

Publisher's PDF, also known as Version of record

Link back to DTU Orbit

Citation (APA):

Jensen, S. H., Graves, C. R., Chen, M., Hansen, J. B., \& Sun, X. (2016). Characterization of a Planar Solid Oxide Cell Stack Operated at Elevated Pressure. Journal of The Electrochemical Society, 163(14), F1596F1604. https://doi.org/10.1149/2.1171614jes

\section{General rights}

Copyright and moral rights for the publications made accessible in the public portal are retained by the authors and/or other copyright owners and it is a condition of accessing publications that users recognise and abide by the legal requirements associated with these rights.

- Users may download and print one copy of any publication from the public portal for the purpose of private study or research.

- You may not further distribute the material or use it for any profit-making activity or commercial gain

- You may freely distribute the URL identifying the publication in the public portal 


\title{
Characterization of a Planar Solid Oxide Cell Stack Operated at Elevated Pressure
}

\author{
S. H. Jensen, ${ }^{a, *, z}$ C. Graves, ${ }^{a, *}$ M. Chen, ${ }^{a}$ J. B. Hansen, ${ }^{b, *}$ and X. Sun ${ }^{a}$ \\ ${ }^{a}$ Department of Energy Conversion and Storage, Technical University of Denmark, Roskilde, Denmark \\ ${ }^{b}$ Haldor Topsoe A/S, Lyngby, Denmark
}

\begin{abstract}
As global and local energy production becomes more dependent on intermittent renewable sources like wind and solar, efficient and reversible conversion of electricity to storable fuels becomes increasingly important. Solid oxide cells (SOCs) are interesting in this context since they can be operated either as electrolyzers (SOEC) to convert electricity to fuels such as hydrogen or methane, and as fuel cells (SOFC) to convert fuels to electricity. Both productivity and conversion efficiency can be improved if the SOC operation pressure can be increased from ambient pressure to 10-30 bar. In this paper we characterize an SOC stack operated at pressures from ambient pressure to 10 bar. The pressure dependency of stack temperature, cell area specific resistance (ASR), current-voltage (iV) curves, stack impedance spectra and pressure drop across the stack and heat exchangers is analyzed in this paper. Additionally, the expected impact on the hydrogen production efficiency and cost is discussed.

(C) The Author(s) 2016. Published by ECS. This is an open access article distributed under the terms of the Creative Commons Attribution 4.0 License (CC BY, http://creativecommons.org/licenses/by/4.0/), which permits unrestricted reuse of the work in any medium, provided the original work is properly cited. [DOI: 10.1149/2.1171614jes] All rights reserved.

(cc) BY
\end{abstract}

Manuscript submitted October 10, 2016; revised manuscript received November 11, 2016. Published November 19, 2016. This was

Paper 3077 presented at the Honolulu, Hawaii, Meeting of the Society, October 2-7, 2016.

Steam electrolysis using solid oxide cells (SOC) has been investigated since the early $1980 \mathrm{~s}$. $^{1-3}$ Research in this non-fossil-based energy storage technology has gradually been intensified during the last two decades due to the recent high oil prices and the increasing climate challenges. SOC stacks generally perform worse and degrade faster than single cells, ${ }^{3}$ but some stacks from Topsoe Fuel Cell (TOFC) ${ }^{4-6}$ and Ceramatec ${ }^{7}$ have shown similar durability as single cells ${ }^{8}$ and button cells ${ }^{9}$ when operated at electrolysis current density less than $\sim 1 \mathrm{~A} \mathrm{~cm}^{-2}$.

Pressurized operation of SOEC stacks is expected to increase the conversion efficiency by 3 to $5 \%$ and reduce auxiliary component costs. $^{10,11}$ Still only a limited number of pressurized long-term durability studies have been published ${ }^{12-17}$ but some pressurized shortterm durability tests using SOC stacks for steam electrolysis exists, reporting respectively $\sim 80 \% \mathrm{kh}^{-113}$ and $\sim 15 \% \mathrm{kh}^{-118}$ voltage increase rates. It should be mentioned that such high degradation rate within the first few hundred hours is also seen in tests at ambient pressure.

The conversion efficiency increase is caused by a decrease of the internal resistance in the cells with increasing pressure. ${ }^{12,13} \mathrm{An}$ increased frequency of reactants hitting the electrochemical reaction sites, ${ }^{19,20}$ and a decrease of the diffusion resistance ${ }^{13,14}$ are the main reasons for the decreased resistance with increasing pressure.

For thermodynamic reasons the open circuit voltage (OCV) increases with increasing pressure. This means that although the resistance decreases with increasing pressure, at low electrolysis current densities the cell operating voltage is more or less unchanged due to the increase in OCV. ${ }^{12,15,16}$

In this paper we present cell area specific resistance (ASR), open circuit voltage (OCV), current-voltage (iV) curves, impedance spectra, and pressure drop across the stack and heat exchangers (HEX) as function of pressure, gas flow rate and gas type. The data is recorded with an 11-cell planar stack supplied from Haldor Topsoe A/S (HTAS) at pressures ranging from 1 bar up to 10 bar. Condensation issues which previously resulted in fluctuating stack voltage at pressures above 3 bar $^{18}$ have successfully been resolved by heat tracing the gas pipes to/from the stack. This allows an improved analysis of recorded data with accurate derivation of the internal resistance and OCV.

The experimental results are used in an estimation of hydrogen production efficiency on the system level as well as the cost using pressurized SOEC technology.

\section{Experimental}

Stack description.-The stack used in this test was produced by HTAS. It contains 11 cells, each with an active area of $87.7 \mathrm{~cm}^{2}$. The anode ${ }^{c}$ supported cells (ASC) consist of a nickel-yttria stabilized zirconia cermet as the hydrogen electrode, yttria stabilized zirconia as the electrolyte, lanthanum strontium cobalt ferrite oxide mixed with cerium gadolinium oxide as the oxygen electrode and cerium gadolinium oxide as a barrier layer between the oxygen electrode and the electrolyte. The individual cells in the stack are connected by coated Crofer interconnects forming a single repeat unit (SRU). The 11 SRUs are stacked between two endplates that act as current terminals. The gas is supplied from the endplates to the electrode compartments by internal manifolds in the cells and interconnects. Glass seals are used to prevent gas mixing between electrode compartments and surroundings. Pressure is not expected to affect the physical integrity of the sealings since the stack was pressurized both inside and outside using passive pressure balancing as described below. However the gas diffusion in the porous support layer under the seals increases with increasing pressure. Further stack information is given elsewhere. ${ }^{6}$

Test setup.-The test setup consists of a pressure vessel which accommodates a furnace, stack housing and manifold, heat exchangers (HEX), $\mathrm{H}_{2} \mathrm{O}$ evaporator, condensation flasks, probes etc. Feedthroughs mounted on flanges provide access for gas tubing, power lines and data acquisition cables to the furnace, SOC stack, sensors and gas handling equipment inside the pressure vessel. A gas handling cabinet placed next to the pressure vessel houses equipment such as mass flow controllers (MFCs), gas sensors, differential pressure sensors (DPSs), reduction valves and pressure controlling systems. The safety of the system is monitored and controlled by a programmable logic controller (PLC) located in a drawer below the gas handling cabinet. Power-electronics to operate the stack in either fuel cell mode or electrolysis mode are placed below the drawer with the PLC. Fig. 1A shows a photo inside the pressure vessel of the high pressure SOC stack test system. The photo shows the fuel gas condenser, heat exchangers inside insulation material, springs for stack compression and evaporator box. Further details about the test system is presented elsewhere. ${ }^{18}$

The gas handling concept is shown schematically in Fig. 1B. The MFCs in the figure are labelled from a to $\mathrm{g}$. $\mathrm{N}_{2}$ was used as sweep gas (with a flow rate of $\sim 300 \mathrm{l} \mathrm{h}^{-1}$ through $\mathrm{MFC}_{\mathrm{f}}$ ) in the entire experiment. This was done to avoid potential leaks from the stack, gas 

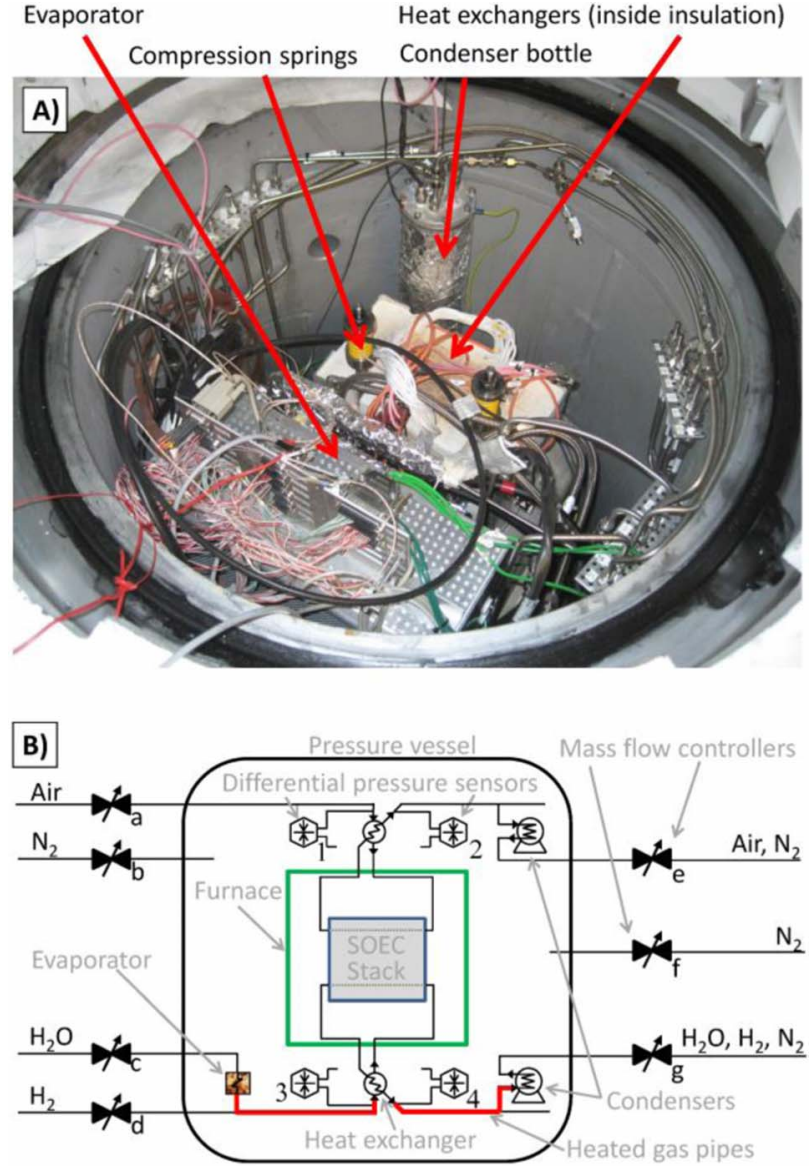

Figure 1. A) Various components inside the pressure vessel. B) Outline of the gas handling concept. A photo of the entire test facility is presented elsewhere. ${ }^{18}$

piping and auxiliary components to cause accumulation of hydrogen and/or oxygen inside the vessel. A pressure sensor (not shown in Fig. 1B) measures the pressure inside the pressure vessel. The pressure in the vessel is controlled by controlling the flow rate of $\mathrm{N}_{2}$ through $\mathrm{MFC}_{\mathrm{b}}$ via a PID loop which takes the measured pressure as input and the $\mathrm{MFC}_{\mathrm{b}}$ flowrate set point as output. In order to balance the pressure between the two electrode compartments of the SOC stack against the pressure in the pressure vessel, the electrode compartment exhaust gas pipes are open toward the pressure vessel (In Fig. 1B shown as small open-ended pipes near the condensers). This ensures practically the same pressure in the pressure vessel as in the electrode compartments. In order to avoid $\mathrm{O}_{2}$ and $\mathrm{H}_{2}$ accumulation in the pressure vessel, the $\mathrm{MFC}_{\mathrm{e}}$ and $\mathrm{MFC}_{\mathrm{g}}$ set points were automatically controlled to ensure a small flow of $\mathrm{N}_{2}$ from the pressure vessel into the fuel and air gas streams. When the SOC stack operates as an electrolyzer or fuel cell it generates or consumes $\mathrm{H}_{2}$ at the negative electrodes and $\mathrm{O}_{2}$ at the positive electrodes. The $\mathrm{MFC}_{\mathrm{e}}$ and $\mathrm{MFC}_{\mathrm{g}}$ set points were automatically adjusted to compensate for these changes to maintain the small flows of $\mathrm{N}_{2}$ from the vessel into the $\mathrm{H}_{2} / \mathrm{H}_{2} \mathrm{O}$ and air gas streams.

The $\mathrm{O}_{2}$ concentration in the pressure vessel was monitored by a sensor (not shown in Fig. 1B). A small amount of $\mathrm{O}_{2}$ was maintained in the pressure vessel to burn off any $\mathrm{H}_{2}$ leaking from the fuel electrode compartment, auxiliary components and gas pipes. The $\mathrm{O}_{2}$ concentration in the pressure vessel was controlled by a PID loop which has the $\mathrm{O}_{2}$ concentration as input and the flow rate set point of $\mathrm{MFC}_{\mathrm{e}}$ as output.

The inlet and outlet pressure before and after the two heat exchangers were measured against the pressure in the pressure vessel with four APR-2000ALW DPSs, each with a measurement range of 0 to 500 mbar \pm 0.5 mbar. The pressure of the entering/exiting gas streams
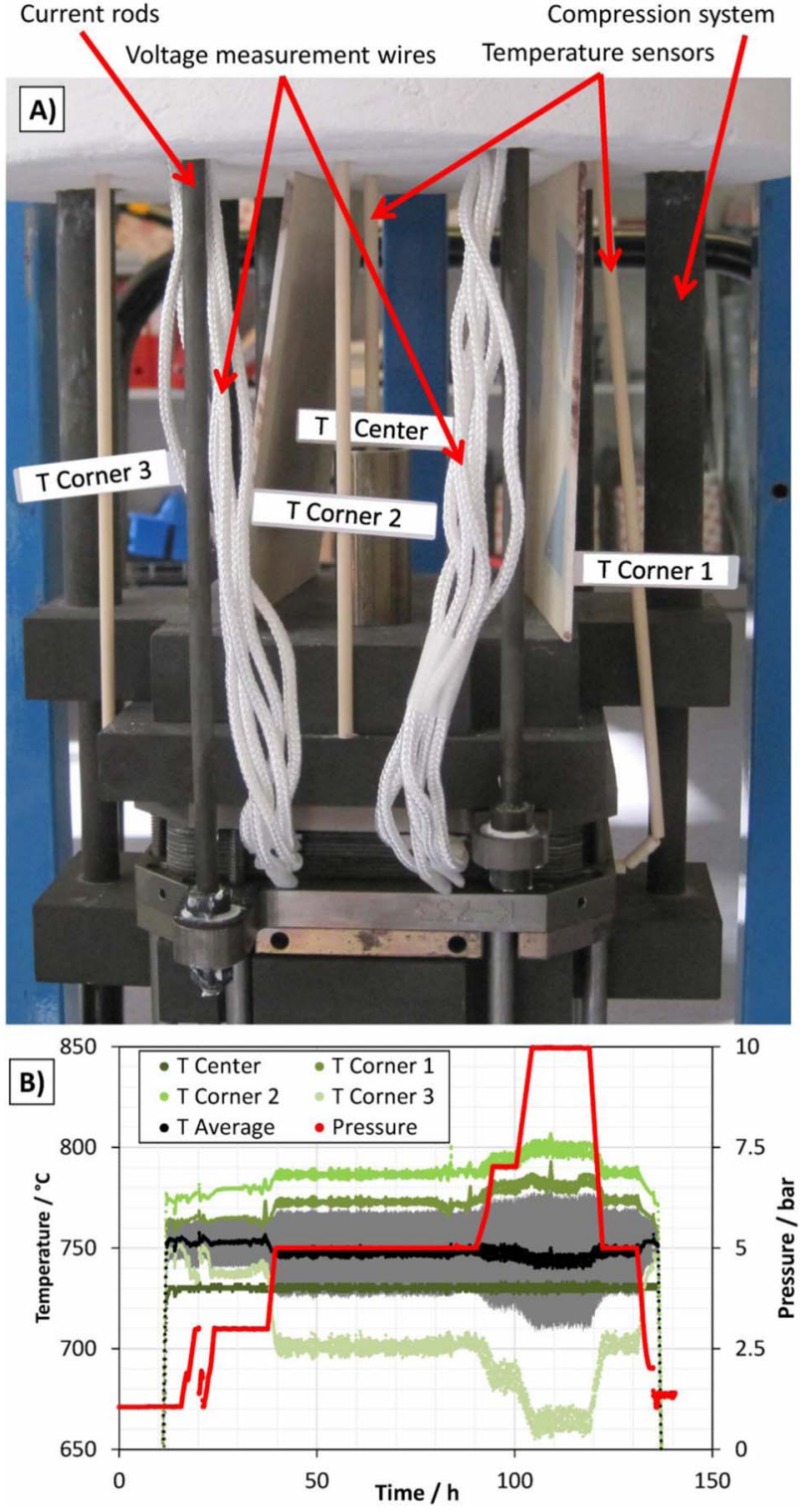

Figure 2. A) Photo of the SOC stack with placement of thermocouples before the stack is placed inside the furnace. B) Temperature as function of time and pressure. The gray shaded area is the standard error calculated from the four temperature measurements.

was measured on the cold side of the heat exchangers, just before the gasses entered/exited the HEX. The DPSs were placed outside the pressure vessel, but for simplicity in the drawing the extra piping was not included in Fig. 1B. Vacuum pumps (not shown in the figure) were used to remove the gas from $\mathrm{MFC}_{\mathrm{e}}, \mathrm{MFC}_{\mathrm{f}}$ and $\mathrm{MFC}_{\mathrm{g}}$, to ensure the stack can be operated at ambient pressure. Here the pressure unit "bar" refers to bar-absolute, which means in this paper 1 bar is the same as atmospheric (i.e. ambient or gauge) pressure.

The gas pipes from the evaporator to the fuel-side HEX and from the fuel-side HEX to the condenser were heat traced, as indicated with red lines in Fig. 1B. This avoids steam condensation which previously affected the fuel flow-stability and stack voltage above 3 bar. ${ }^{18}$

The stack temperature was controlled by a furnace controller connected to a thermocouple placed above the SOC stack ("T Center" in Fig. 2A). The thermocouple was placed inside an alumina rod which was placed inside a short piece of metal pipe. Additionally, the stack temperature was measured with three thermocouples. Their placement is also shown in Fig. 2A. "T Corner 1" and "T Corner 3" were placed 
inside a $\sim 10 \mathrm{~mm}$ deep hole in the stack bottom and top plate, respectively. "T Corner 2 " contacted one of the metal plates sandwiching the stack.

Startup procedure.-At start up, first the stack was heated to $850^{\circ} \mathrm{C}$ and the $\mathrm{NiO}$ in the fuel electrodes reduced with a mixture of $\mathrm{H}_{2}$ and $\mathrm{N}_{2}$ supplied to the fuel electrode compartment. The temperature was subsequently lowered to $750^{\circ} \mathrm{C}$ for performance characterization at various pressures. During pressure changes, the pressure ramp rate was kept below 1 bar $^{-1}$ and the pressure differences between the pressure vessel and two electrode compartments were kept below \pm 50 mbar.

Test Conditions.-OCV, impedance, area specific resistance (ASR) and iV curve measurements were conducted at two test conditions $\mathrm{A}$ and $\mathrm{B}$ at pressures ranging from 1 bar to 10 bar. Test Condition $\mathrm{A}$ and $\mathrm{B}$ were similar except for the gas compositions and flow rates as this allows electrode-specific characterization. For test condition A, the nominal steam flow rate was $400 \mathrm{l} \mathrm{h}^{-1}$ and for test condition $\mathrm{B}$ it was $200 \mathrm{l} \mathrm{h}^{-1}$. The nominal hydrogen flow rate to the stack fuel electrodes was $400 \mathrm{l} \mathrm{h}^{-1}$ in both test conditions. The nominal air flow rate was $8001 \mathrm{~h}^{-1}$ in test condition $\mathrm{A}$ and $400 \mathrm{l} \mathrm{h}^{-1}$ in test condition B. The flow rate of $\mathrm{MFC}_{\mathrm{c}}$ (Brooks Quantim QMBC4L, Fig. 1B) was measured after the experiment by weighing the water from the MFC outlet. It was found that the actual flow rates were $18 \%$ $\pm 1 \%$ higher than the nominal flow rates used in the presented iV curve and impedance measurements. The flow rate of $\mathrm{MFC}_{\mathrm{d}}$ (Brooks SLA5850S) was measured with a Bios Definer 220-M C1 and was found to be $5 \% \pm 2 \%$ lower than the nominal flow rates used in the presented iV curve and impedance measurements. Using these MFC calibration measurements actual flow rates were calculated. Nominal and actual flow rates as well as steam concentrations for the two test conditions are presented in Table II.

OCV, ASR, iV and impedance measurements.-OCV for the individual cells were measured at $0 \mathrm{~A} \mathrm{~cm}^{-2}$ for test condition $\mathrm{A}$ and B. ASR was obtained as the absolute voltage difference between cell OCV and the cell voltage measured at $\pm 0.03 \mathrm{~A} \mathrm{~cm}^{-2}$, divided by
$0.03 \mathrm{~A} / \mathrm{cm}^{2}$. The ASR measurement was conducted in both electrolysis mode and in fuel cell mode for test condition A but only in electrolysis mode for test condition B.

The stack and cell performance was further characterized with iV curves and impedance spectroscopy. The total electrode area in the stack was $965 \mathrm{~cm}^{2}$, which gives area specific actual flow rates of $0.88 \mathrm{l} \cdot \mathrm{h}^{-1} \cdot \mathrm{cm}^{-2}$ and $0.64 \mathrm{l} \cdot \mathrm{h}^{-1} \cdot \mathrm{cm}^{-2}$ to the fuel electrodes in test condition $\mathrm{A}$ and $\mathrm{B}$, respectively; and $0.83 \mathrm{l} \cdot \mathrm{h}^{-1} \cdot \mathrm{cm}^{-2}$ and 0.41 $1 \cdot \mathrm{h}^{-1} \cdot \mathrm{cm}^{-2}$ to the oxygen electrodes in test condition A and B, respectively. During iV curve acquisitions in SOFC and SOEC mode, a current step of $\sim 0.01 \mathrm{~A} \mathrm{~cm}^{-2}$ was applied. Each step lasted $\sim 50 \mathrm{sec}-$ onds while the voltage of the entire stack and each cell was measured.

The stack impedance was measured from $25 \mathrm{kHz}$ to $0.1 \mathrm{~Hz}$ with normal single sine wave impedance spectroscopy using a Solartron 1260 in combination with an external shunt and a voltage bias compensation system. A Kepco BOP 50-4 M was used to boost the $16 \mathrm{~mA}$ AC current from the Solartron to 1 Ampere AC i.e. with an AC current density of $\sim 0.01 \mathrm{~A} \mathrm{~cm}^{-2}$. The measurement system is described in further detail elsewhere. ${ }^{21}$ From the $\mathrm{iV}$ curves, the area specific resistance (ASR) of the individual cells within the stack was found to be $\sim 0.5 \Omega \mathrm{cm}^{-2}$. This means the voltage pertubation amplitude used to record the impedance spectra was $\sim 5 \mathrm{mV}$ on the individual cells. This means a linear relationship between current and polarization voltage can be assumed.

\section{Results}

Pressure drop across the stack.-Fig. 3 shows the difference between the pressure of the inlet gas before it enters the heat exchanger (HEX) and the pressure of the outlet gas after it exits the HEX, i.e. the pressure drop across the stack and the HEX. The pressure difference was measured using the DPSs presented in the gas flow diagram in Fig. 1B at various inlet gas pressures, gas flows and gas types. More specifically on the fuel gas side the pressure difference is measured as the differential pressure measured by DPS $_{1}$ minus the differential pressure measured by $\mathrm{DPS}_{2}$, assuming that the pressure in the vessel is the same at all places inside the vessel. The pressure difference on the air-side is measured in a similar way. The error bars in Fig. 3 is
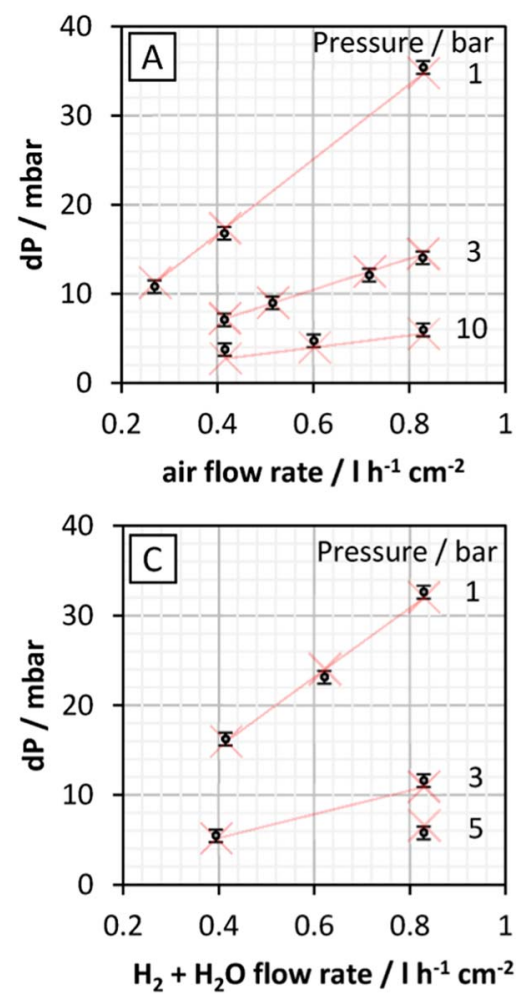
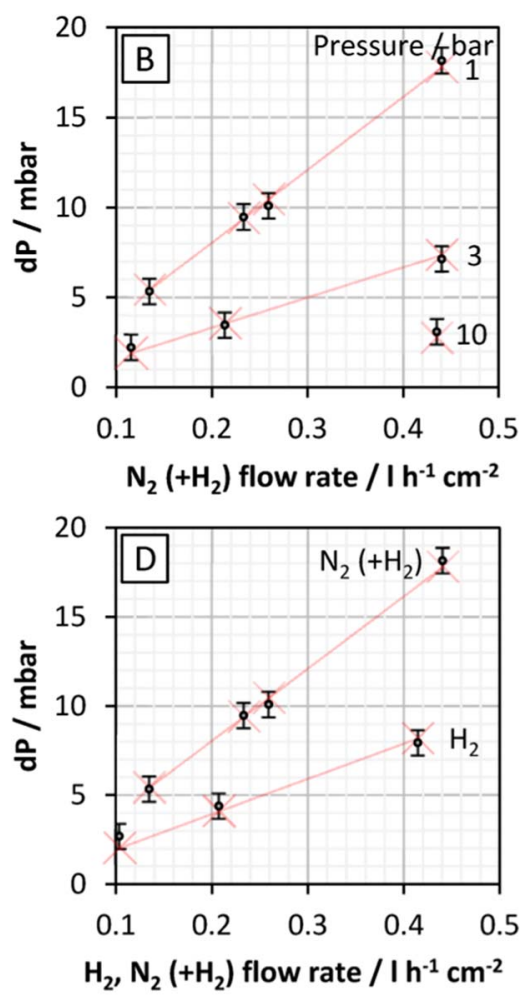

Figure 3. $\Delta P$ across the stack and heat exchangers as a function of gas pressure, flow rate and gas type. The variations in pressure and gas flow rate were conducted with A) Air. B) Dry $\mathrm{N}_{2}$ gas with $\mathrm{H}_{2}$ where the $\mathrm{H}_{2}$ concentration ranges between 6 and 23 vol\%. C) The gas composition used in test condition A (Table II), but at different flow rates. D) Dry $\mathrm{H}_{2}$ at 1 bar compared with the data in B) recorded at 1 bar. Error bars are 0.7 mbar. Red crosses present model results using Equation 1 with the values given in Table I. 
Table I. Values used in Equation 1 to model $\Delta \mathrm{P}$ in Fig. 3.

\begin{tabular}{cccc} 
Fig. 3 part & Gas type & $\gamma^{-1}$ & $\beta$ \\
\hline A & Air & 0.795 & 42.0 \\
B & $\mathbf{N}_{\mathbf{2}}\left(+\mathbf{H}_{\mathbf{2}}\right)$ & 0.801 & 40.5 \\
C & $\mathbf{H}_{\mathbf{2}}+\mathbf{H}_{\mathbf{2}} \mathbf{O}$ & 0.978 & 38.7 \\
D & $\mathbf{H}_{\mathbf{2}}$ & $0.801^{*}$ & 19.8
\end{tabular}

*Fixed at same value as for part B.

\pm 0.7 mbar which is taken as the standard deviation of the two DPS measurements with sensor uncertainties of 0.5 mbar. Based on HEX manufacturer calculations the pressure drop across the HEX is estimated to be less than $20 \%$ of the total pressure difference. This means the pressure difference primarily reflects the pressure drop across the stack.

The measured pressure is modelled using the following equation

$$
\Delta P=\beta \dot{\nu} P^{-\gamma^{-1}}
$$

where $\dot{v}$ is the flow rate and $\beta$ and $\gamma$ are fitting variables. Obtained fitting values for the various gasses are presented in Table I. The model data is presented as red crosses and the red lines are guidance to the eye in Fig. 3.

Stack temperature.-Including the thermocouples used to control the stack temperature, four thermocouples measured the stack temperature. The placement of the temperature sensors is shown in Fig. 2A. T Corner 1 and 3 were placed inside a $\sim 1 \mathrm{~cm}$ deep hole in the top and bottom plate. T Center and T Corner 2 were placed such that the tip of the thermocouple touches the steel plates. T Center was used to control the temperature inside the furnace. The measured temperatures, the average temperature for the four probes and stack pressure as function of time is shown in Fig. 2B. It is seen that before pressurization at 1 bar the deviations between the temperature measurements are quite small. The gray area is the standard error calculated from the four temperature measurements. Once the pressure is increased the average temperature remains relatively close to $750^{\circ} \mathrm{C}$, but the temperature differences and thus the standard error drastically increases.
When the pressure is decreased to ambient pressure the temperature differences also decrease to the initial level.

Open Circuit Voltage (OCV).-Single cell OCV measurements as function of pressure are presented in Fig. 4. The OCV measurements were conducted for both test condition A and B. Horizontal lines show the OCV calculated using the Nernst equation and the actual flow rates (gas compositions) presented in bold in Table II. The colored areas around the horizontal lines indicate the uncertainty in the OCV measurement, based on the uncertainty (standard error) in the temperature measurement described in the previous section; the standard error is added/subtracted from the average temperature in the Nernst equation.

Area specific resistance $(A S R)$.- $-\mathrm{ASR}$ measurements in both SOEC and SOFC mode for test condition A and for SOEC mode for condition B (Table II) are presented in Fig. 5. The ASR was obtained as the absolute voltage difference between cell OCV and the cell voltage measured at $\pm 0.03 \mathrm{~A} \mathrm{~cm}^{-2}$, further divided by $0.03 \mathrm{~A} / \mathrm{cm}^{2}$.

Electrochemical impedance spectroscopy (EIS).- -Stack impedance spectra were recorded at test condition A and B at 1-10 bar. The spectra are presented in Fig. 6. One of the spectra in Fig. $6 \mathrm{C}$ was recorded at test condition A but with $4001 \mathrm{~h}^{-1}$ air instead of $800 \mathrm{l} \mathrm{h}^{-1}$ and is therefore referred to as $\mathrm{A}^{\prime}$. Differences between the imaginary parts of selected spectra are presented in Fig. 6D.

Current-Voltage (iV) curves.-Stack iV curves at pressures from 1 bar to 10 bar are shown in Fig. 5. Based on the actual flow rates (Table II), the $\mathrm{H}_{2}$ and $\mathrm{O}_{2}$ (in the air supply) utilization was 53\% and $61 \%$, respectively at maximum current density $\left(0.51 \mathrm{~A} \mathrm{~cm}^{-2}\right)$ in fuel cell mode in test condition $\mathrm{A}$. The actual $\mathrm{H}_{2} \mathrm{O}$ utilization at maximum current density in electrolysis mode $\left(-0.51 \mathrm{~A} \mathrm{~cm}^{-2}\right)$ was $44 \%$ and $88 \%$ in test condition A and B, respectively. Cell iV curves for the two test conditions are presented in the supplementary material, Figs. S1-S8.

Constant Current Operation.-A 5h constant current density test was conducted to check the stack voltage stability. The stack and cell voltages are shown in Fig. 8.
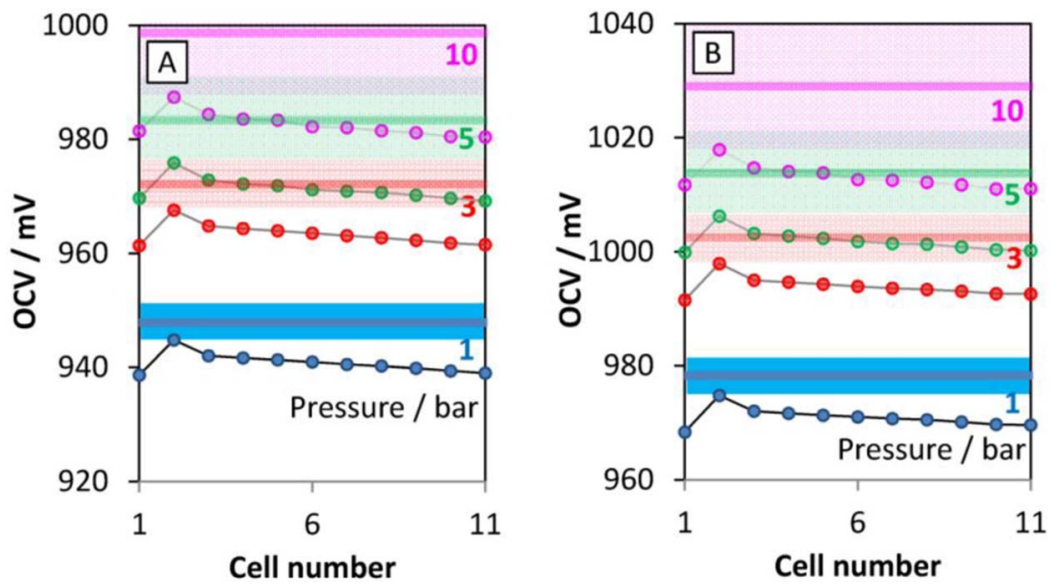

Figure 4. Cell OCV as function of stack pressure recorded with A) Test condition A, and B) Test condition B. The thick horizontal lines are the corresponding Nernst voltages for the relevant gas compositions and pressures. The colored areas indicate the Nernst voltage uncertainties due to the temperature uncertainties (gray area in Fig. 2B).

Table II. Gas flow rates and $\mathrm{H}_{2} \mathrm{O}$ concentrations in the experiments.

\begin{tabular}{cccccc} 
Test condition & Gas type & Nominal flow rate $1 \mathrm{~h}^{-1}$ & Actual flow rate $1 \mathrm{~h}^{-1}$ & Actual $\mathrm{H}_{2} \mathrm{O}$ concentration & Measured $\mathrm{H}_{2} \mathrm{O}$ concentration \\
\hline A & Air $/ \mathbf{H}_{\mathbf{2}} \mathbf{O} / \mathbf{H}_{\mathbf{2}}$ & $800 / 400 / 400$ & $\mathbf{8 0 0}^{*} / \mathbf{4 6 9} / \mathbf{3 8 4}$ & $\mathbf{5 5 . 0 \%}$ & $56.8 \%$ \\
B & $\mathbf{A i r} / \mathbf{H}_{2} \mathbf{O} / \mathbf{H}_{2}$ & $400 / 200 / 400$ & $\mathbf{4 0 0}^{*} / \mathbf{2 3 5} / \mathbf{3 8 4}$ & $\mathbf{3 8 . 0 \%}$ & $39.9 \%$
\end{tabular}

*No air flow rate calibration measurement available.

${ }^{\dagger}$ Measured at 1 bar and $750^{\circ} \mathrm{C}$ using OCV for cell 2 (Fig. 4). 

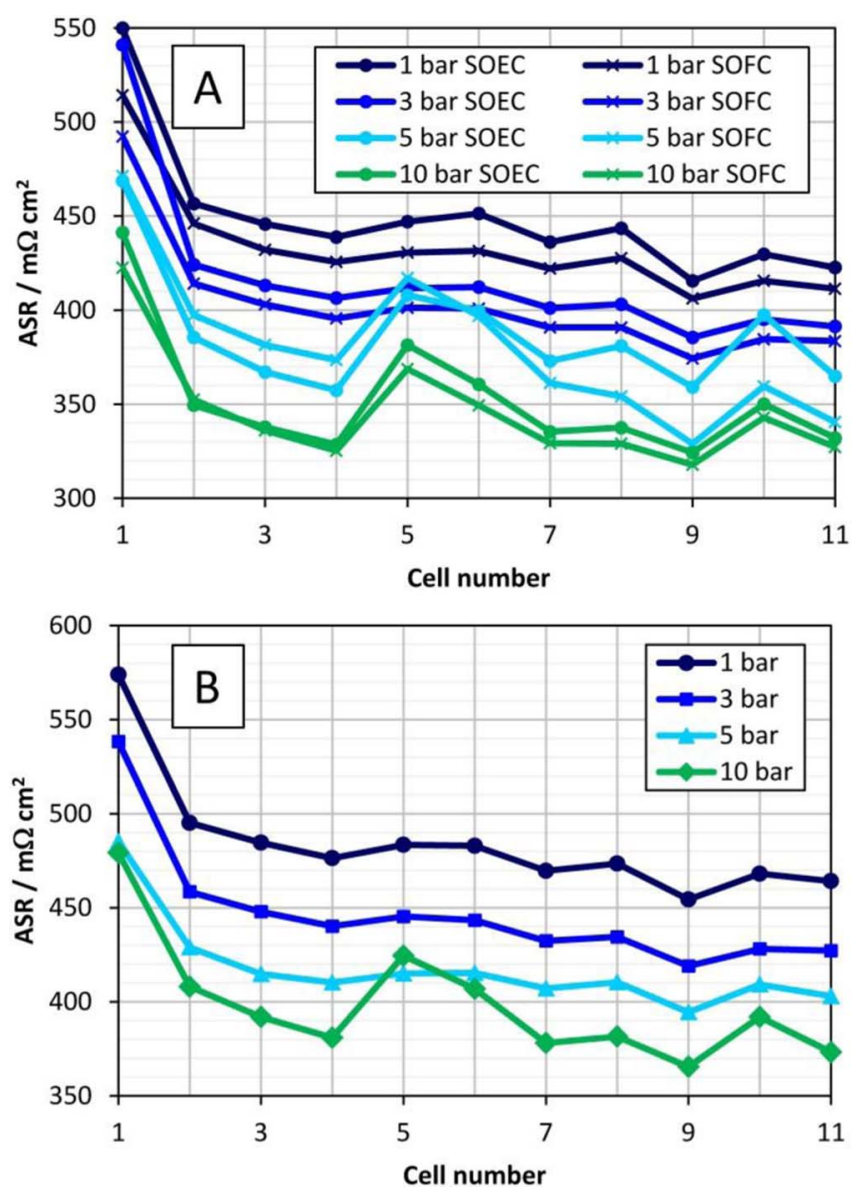

Figure 5. Cell ASR as function of stack pressure recorded at A) Test condition $\mathrm{A}$ in SOEC and SOFC modes and B) Test condition B in SOEC modes.

\section{Discussion}

Pressure drop across the stack.-In Fig. 3, the pressure drop across the heat exchanger and stack is presented for various gas flows, gas types and pressures. Equation 1 was used to fit the data and the obtained values for $\gamma^{-1}$ and $\beta$ are presented in Table I. The obtained values for $\gamma^{-1}$ can be compared with values previously reported for a similar stack pressure test conducted at pressures up to 25 bar but without variations in gas composition and flow rate. ${ }^{18}$ Here it is proposed that $\gamma^{-1}$ deviates from 1 because the gas inside the stack has limited heat exchange with the surroundings outside the stack. Assuming the pressure drop along the gas channels $\Delta P$ is isentropic and follows a Darcy-law expression, it was concluded that $\Delta P \propto P^{-\gamma^{-1}}$ where $\gamma$ is the ratio between the specific heat constants $C_{P}$ and $C_{v}$.

Based on the specific heat constants, the theoretical value for $\gamma^{-1}$ is 0.71 for air, $\mathrm{N}_{2}$ and $\mathrm{H}_{2}$ and 0.75 for $50 \mathrm{vol} \% \mathrm{H}_{2} \mathrm{O}+50 \mathrm{vol} \% \mathrm{H}_{2}$. The values obtained for $\gamma^{-1}$ in the previous work ${ }^{18}$ and in this work (Table I) are higher than the theoretical values. The discrepancy is assumed to be related to a partial heat exchange with the surroundings when the gas passes through the stack.

Besides the dependency of the inlet gas pressure, Equation 1 expresses the pressure drop across the stack as function of gas flow rate. As for the power-law constant $\gamma^{-1}$, also the constant $\beta$ depends on the gas-type. The obtained fitting values for $\beta$ are presented in Table I.

From Fig. 3 the model is seen to provide a good fit to the data. Comparing values in row 1 and 2 in Table $I$ it is noted that the values for $\beta$ and $\gamma^{-1}$ are quite similar for air and $\mathrm{N}_{2}$ (with a small amount of $\mathrm{H}_{2}$ ), indicating similar gas drop behavior on the fuel and air side of the stack. When the fuel gas is changed to $50 \mathrm{vol} \% \mathrm{H}_{2} \mathrm{O}+50 \mathrm{vol} \%$
$\mathrm{H}_{2}, \beta$ decreases slightly whereas $\gamma^{-1}$ changes considerably. ${ }^{\mathrm{d}}$ Since the pressure drop with pure $\mathrm{H}_{2}$ was only measured at ambient pressure (Fig. 3D) $\gamma^{-1}$ was fixed at 0.801 , the value obtained from the fit of the data in Fig. 3B. With this value a significantly smaller value for $\beta$ was obtained for pure $\mathrm{H}_{2}$ than for $\mathrm{N}_{2}$ containing small amounts of $\mathrm{H}_{2}$ which is ascribed to the significantly larger diffusion coefficient for $\mathrm{H}_{2}$ than for $\mathrm{N}_{2}$.

$\Delta P$ vs. flow rate is almost linear in Fig. 3 and can therefore be fitted reasonably with a linear Darcy-term $(\beta \dot{\nu})$. An additional quadratic Forchheimer term would be required for higher flow rates ${ }^{22,23}$ and correspondingly higher Reynold numbers/Forchheimer numbers. ${ }^{24}$

It is important to note that the decrease in the pressure drop across the stack with increasing pressure can help relaxing the constraints on the dimensions of the gas-channels inside the stack which could potentially open up for new designs with higher contact areas between the various layers in the stack, thereby decreasing the ASR and degradation issues due to interconnect/cell contact loss.

Stack temperature.-The apparent temperature distribution across the four thermocouples (TCs) measuring the stack temperature changes dramatically with pressure. The reason for this change is possibly related to a change in the temperature of the gas inside the furnace. With increasing pressure, the heat dissipation increases from the furnace to the pressure vessel interior. This was previously observed as an increases in the temperature inside the pressure vessel. ${ }^{18}$ With the increased heat dissipation, the temperature difference between top and bottom inside the furnace most likely also increases.

Importantly, the cylindrical shape of the furnace suggests that at equal heights inside the furnace the temperature variations are limited. In addition to this, the thick metal plates sandwiching the stack helps minimize the in-plane temperature distribution.

The large temperature variations of the gas inside the furnace at high pressure highlight a technological benefit attainable by SOCs operated at $\sim 500-600^{\circ} \mathrm{C}$. Such low SOC operating temperatures enables hot pressure bearing constructions (housing) around the stack such that the insulation material can be operated at ambient pressure where it provides the best insulation.

Open circuit voltage (OCV).-From the OCV measurement for cell 2 (Fig. 4), an apparent $\mathrm{H}_{2} \mathrm{O}$ concentration of $56.8 \%$ and $39.9 \%$ was obtained using the Nernst equation for test condition A and B, respectively. Based on the calibrated flow rates, the $\mathrm{H}_{2} \mathrm{O}$ concentrations were $55.0 \%$ and $38.0 \%$ for test condition $\mathrm{A}$ and $\mathrm{B}$, respectively (see Table II). The apparent deviation between the $\mathrm{H}_{2} \mathrm{O}$ concentration at cell 2 and the concentration calculated with the actual flow rates is slightly less than $2 \%$ for both test conditions. The deviation is either a real deviation in $\mathrm{H}_{2} \mathrm{O}$ concentration and thus caused by inaccuracies in the flow rate calibrations or by leaks in seals or cells. Alternatively the deviation could be caused by errors in the stack temperature measurements (Fig. 2B) as indicated by the colored areas.

The relative distribution of OCV doesn't change much with pressure, indicating limited changes in the flow distribution between the cells due to the increased gas pressure. The OCV for cell 2 is higher than the OCV at cell 1 . From cell 3 to cell 11 the OCV gradually drops about $0.17 \%$ per cell. Leaks at the internal manifolding seals could possibly explain this gradual voltage drop: When the fuel gas flows through the internal gas channels from the bottom plate toward the top plate, air leaking to the fuel gas will decrease the hydrogen concentration and increase the steam concentration, such that the cells farthest away from the bottom plate where the gas enters the stack experience the highest humidity.

\footnotetext{
${ }^{\mathrm{d}}$ The stability of the flow rate of humid fuel gasses to the stack was improved relative to a previous stack test ${ }^{18}$ by heating the inlet gas to/from the HEX as shown in Fig. 1B. This improved the pressure fluctuations and thus the $\Delta P$ measurement precision. However, above $\sim 5$ bar some uncertainties remained with humid gasses. This is due to condensation in the long (and ambient-temperature) pipes to the DPS's, remembering the DPS's were placed outside the pressure vessel. Since in Fig. 3C, the pressure difference was only measured up to 5 bar the uncertainty on the measured value of $\gamma^{-1}$ is relatively high.
} 

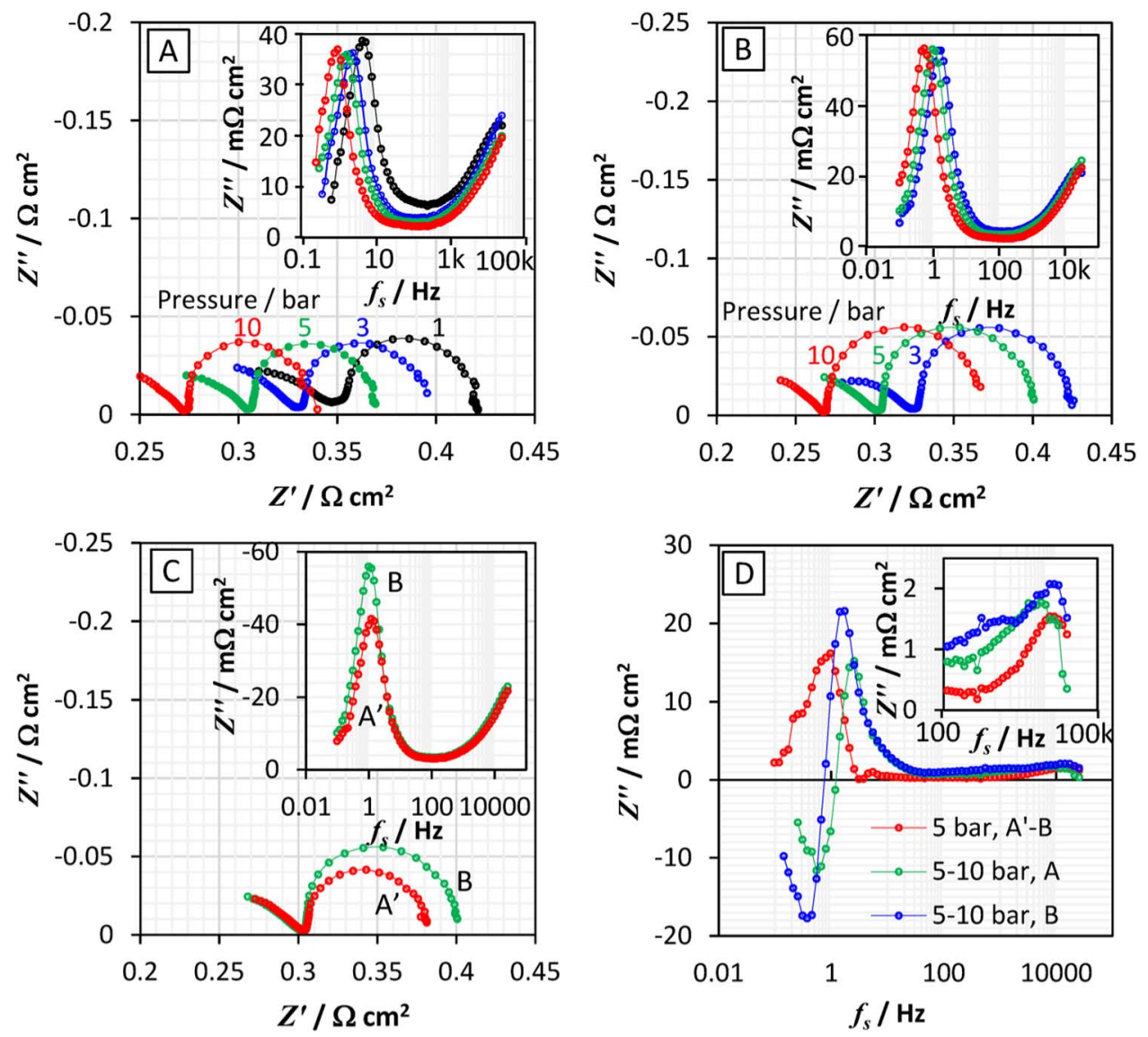

Figure 6. Nyquist plots of stack impedance spectra recorded at A) Test condition A, B) Test condition B and C) at 5 bar comparing the spectra recorded at test condition $\mathrm{A}^{\prime}$ and $\mathrm{B}$ where test condition $\mathrm{A}^{\prime}$ had a nominal flow rate of $400 \mathrm{l} / \mathrm{h}$ air instead of $800 \mathrm{l} / \mathrm{h}$ air, and similar $\mathrm{H}_{2} /$ steam flow rates as test condition $\mathrm{A}$. The insets show Bode plots of the spectra. A Bode plot of the differences of the imaginary part of selected spectra is presented in D). The red spectrum is the difference between the spectra in C), the green and blue spectra are the difference between the spectra recorded at 5 and 10 bar at test condition A and B, respectively. The inset shows a zoom of the high-frequency part of the Bode plot.

In a previous stack test with a similar stack, ${ }^{18}$ leak tests with $\mathrm{H}_{2}$ diluted in $\mathrm{N}_{2}$ indicated that the leak rate was relatively constant around $3 \mathrm{l} \mathrm{h}^{-1}$ at 3 bar and up to 25 bar. The OCV is seen to increasingly deviate from the Nernst voltage calculated with the actual flow rates. ${ }^{\mathrm{e}}$ For all pressures, the OCV for cell 2 is at the lower edge of the $\mathrm{OCV}$ uncertainty. This indicates that an erroneous stack temperature measurement could partially explain the increasing deviation between OCV and Nernst voltage with pressure.

Area specific resistance (ASR).-Cell ASR at test condition A and B is presented in Fig. 5. The bottom cell (Cell 1) is seen to have a higher ASR than the remaining 10 cells which have quite similar ASR. This is also seen in the cell iV curves (Figs. S1-S8). The larger ASR for cell 1 is possibly related to poor endplate contacting.

It is seen that the ASR for cell 5 and 6 increases relative to the other cells between 3 and 5 bar in Fig. 5A. The same relative increase in cell ASR for cell 5 and 6 is seen between 5 and 10 bar in Fig. 5B. The relative increase in ASR was caused by a short period with oxygen starvation at the air electrodes due to an $\mathrm{iV}$ curve recorded at 5 bar in SOFC mode but with a too low nominal air flow of $4001 \mathrm{~h}^{-1}$. The oxygen starvation occurred after the 5 bar ASR data in Fig. 5B was recorded, and before the 5 bar ASR data in Fig. 5A was recorded. The $\mathrm{iV}$ curve recorded with too low air flow was stopped by the surveillance software when the individual cell voltages were below $600 \mathrm{mV}$, but apparently a few cells were affected by the oxygen shortage which

eAn increasing deviation with pressure between Nernst voltage and OCV was also observed from 1.2 bar to 25 bar in the previous stack test. ${ }^{18}$ lasted less than a minute. The 5 bar ASR data presented in Fig. 5A was measured shortly after the oxygen starvation incident and the iV curves at 10 bar were recorded a number of hours later (indicated by the pressure curve in Fig. 2B). Cell 7-11 seems to recover after being temporarily affected by the $\mathrm{O}_{2}$ starvation. The $\mathrm{iV}$ curve recorded with a nominal air flow of $4001 \mathrm{~h}^{-1}$ is presented as Fig. S9 and the related ASR (secant values) as function of current density is presented in Fig. S10.

In general the ASR was seen to decrease with increasing pressure. The same trend has been observed previously on stacks, single cells and electrodes. ${ }^{12,13,15,20,25}$

Besides the effects of the $\mathrm{O}_{2}$ starvation incident at 5 bar, the ASR distribution across the cells is seen to be reasonably stable with pressure. This indicates that the temperature from cell to cell within the stack is fairly independent of pressure.

As mentioned in section Stack temperature the cylindrical shape of the furnace and the thick steel plates sandwiching the stack ensures the in-plane temperature variations are limited. It is therefore concluded that the large temperature variations seen at high pressure (Fig. 2B) are likely not present inside the stack.

Electrochemical impedance spectroscopy (EIS).- - In agreement with previous observations, ${ }^{18}$ the spectra in Fig. 6 show how the summit frequency of the gas conversion arc (low frequency arc with summit frequency around $1 \mathrm{~Hz}$ ) decreases with increasing pressure, and that the size of the arc are relatively independent of pressure. This is also confirmed by heart-beat shape at low frequency for the green and blue difference spectra in Fig. 6D. 

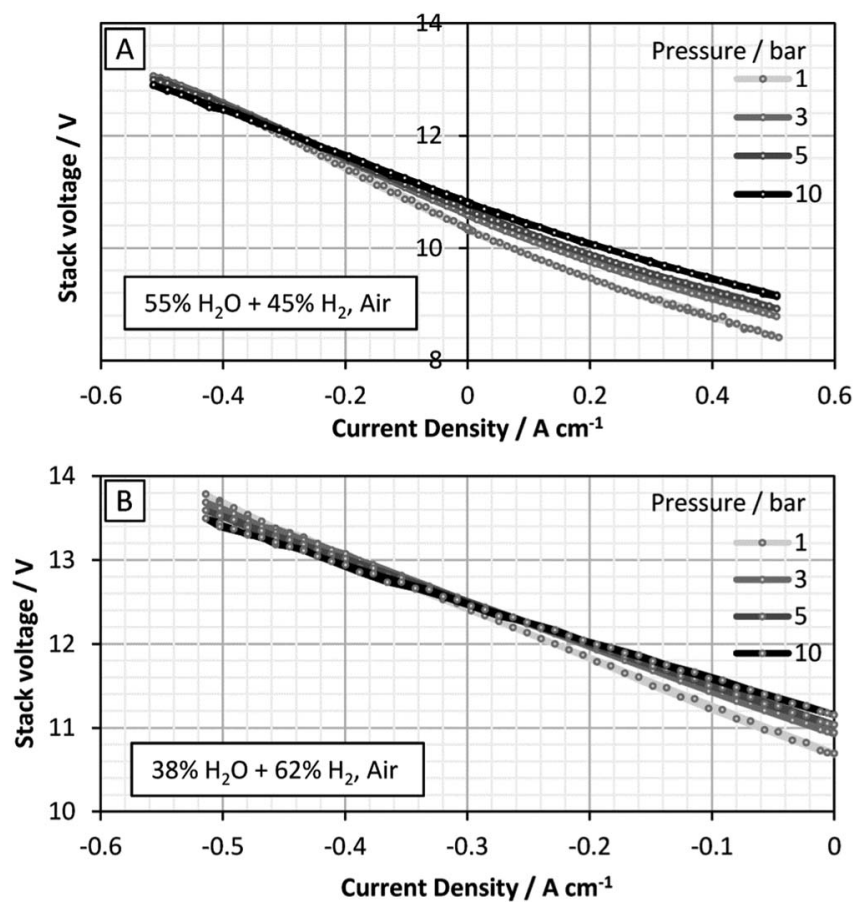

Figure 7. Stack iV curves recorded at $750^{\circ} \mathrm{C}$ and $1-10$ bar at A) Test condition A and at B) Test condition B. Gas concentrations for the fuel and air electrodes are presented in the figure part. The test conditions are further specified in Table II.

From the red difference spectra recorded at 5 bar in Fig. 6D, it is seen that the high-frequency arc with a summit frequency around 10 $\mathrm{kHz}$ is affected by the steam partial pressure at the fuel electrodes. A shift in nominal steam concentration from $50 \%$ to $25 \%$ was conducted at 1 bar on a similar stack. ${ }^{18}$ Here the summit frequency for the highfrequency arc was slightly below $10 \mathrm{kHz}$ indicating that the summit frequency of this arc increases with increasing pressure. From the zoom in Fig. 6D it is seen that the size of this arc decreases with pressure (green and blue spectrum).

Current-voltage (iV) curves.-Stack and cell iV curves were recorded at pressures ranging from 1-10 bar. The stack iV curves are presented in Fig. 7 and cell iV curves in Fig. S1-S8. The increasing OCV and decreasing ASR with increasing pressure follows the trend observed previously. ${ }^{18}$ It is interesting to note how the stack iV curves tend to become straight lines with increasing pressure. This is possibly related to the increased heat exchange with the gas surrounding the stack, i.e. the stack is less cooled/heated during the iV curves at high pressure. Gas diffusion differences between SOEC and SOFC operation also decrease with increasing operation pressure due to a decreasing Knudsen diffusion with increasing pressure in the electrodes and the support layers. This correlates with decreasing differences between the measured cell ASR in SOEC and SOFC mode with increasing pressure (Fig. 5A, ignoring the dynamic effects at 5 bar).

The temporary oxygen starvation described in section Area specific resistance explains the redistribution of the cell iV curves between 3 and 5 bar for test condition A (i.e. changing which cells show the lowest iV curve slope and related ASR) as seen in supplementary Figs. S1-S4. Similarly the oxygen starvation explains the redistribution occurring between 5 and 10 bar for test condition B (Figs. S5-S8).

Constant current test.-The stack voltage is reasonably stable during the $5 \mathrm{~h}$ constant current density $\left(-0.34 \mathrm{~A} \mathrm{~cm}^{-2}\right)$ test (Fig. 8) demonstrating that the issues with unstable steam supply due to condensation in a previous test with a similar 11-cell HTAS stack operated at $-0.25 \mathrm{~A} \mathrm{~cm}^{-218}$ is effectively avoided by heating the gas pipes

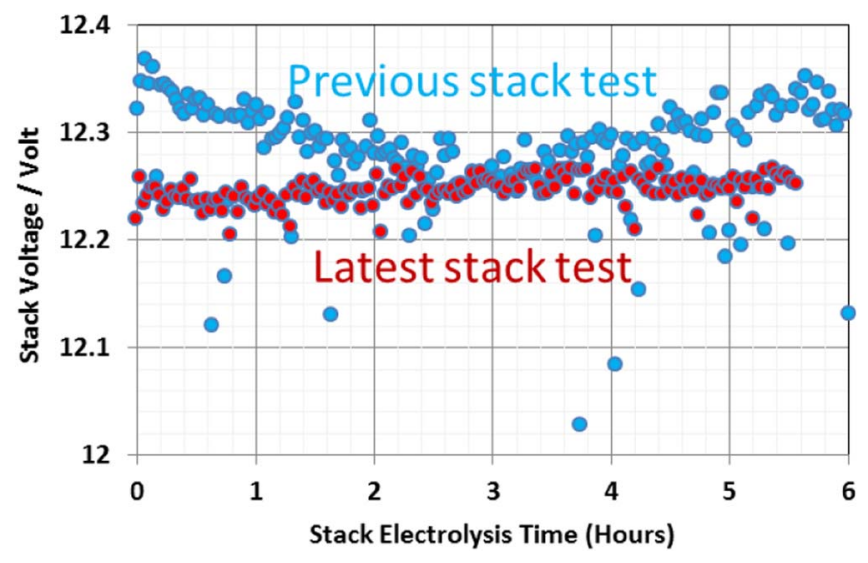

Figure 8. Stack voltage during constant current operation in a previous stack test $^{18}$ compared with the more stable stack voltage in this test with improved steam supply with heat tracing of the fuel stream to/from the stack.

to/from the stack. Both stacks were operated at nominally $4001 \mathrm{~h}^{-1}$ $\mathrm{H}_{2}+4001 \mathrm{~h}^{-1} \mathrm{H}_{2} \mathrm{O}$ supplied to the fuel electrodes and $8001 \mathrm{~h}^{-1}$ air supplied to the air electrodes.

System energy efficiency.-Almost all of the end use applications for electrolytic produced hydrogen (or synthesis gas in the case of co-electrolysis) require elevated pressures as shown in Table III for some of the most relevant end products for future Power to Product technologies.

If SOEC stacks were only able to operate at atmospheric pressure the hydrogen would need to be compressed mechanically.

In practice diaphragm or piston type compressors are used which approximate isentropic performance and they have at best a polytrophic efficiency around $80 \%$ due to friction, bypasses etc. In addition, there is a mechanical loss of around $4 \%$ in the drive motor.

Calculations have been carried out using proprietary Haldor Topsøe A/S software employing sophisticated equations of state, which has proven to be accurate even at high hydrogen pressures. The results are shown on Fig. 9.

In the practical isentropic and polytropic cases the compression has been broken into several steps with compression ratios around 2.7 and intercooling to $20^{\circ} \mathrm{C}$, as this gives better effciency as well as limits the maximum outlet temperature from the compression steps to below $150^{\circ} \mathrm{C}$, which is the maximum allowable for safety and durability reasons.

The most demanding case is delivery of hydrogen for mobile application as in PEMFC vehicles, where the trend is to store the hydrogen at 700 bar on board the vehicle and at 900 bar for the final storage vessel at the dispensing station.

In this case the minimum, theoretical work for compression would be $7.4 \%$ of the lower heating value of hydrogen which is $3 \mathrm{kWh} \mathrm{Nm}^{-3}$. In practice the practical compression energy would be closer to at least $11.4 \%$ of LHV.

The relationship between the required compression work for hydrogen and pressure is close to linear with the logarithms of the pressure except for the highest pressure where the nonidealities becomes

\section{Table III. Typical operating pressure for different hydrogen} applications.

End use

Hydrogen

Methane (SNG)

Methanol
Operating pressure (bar abs)

$10-900$
$20-50$
$50-140$




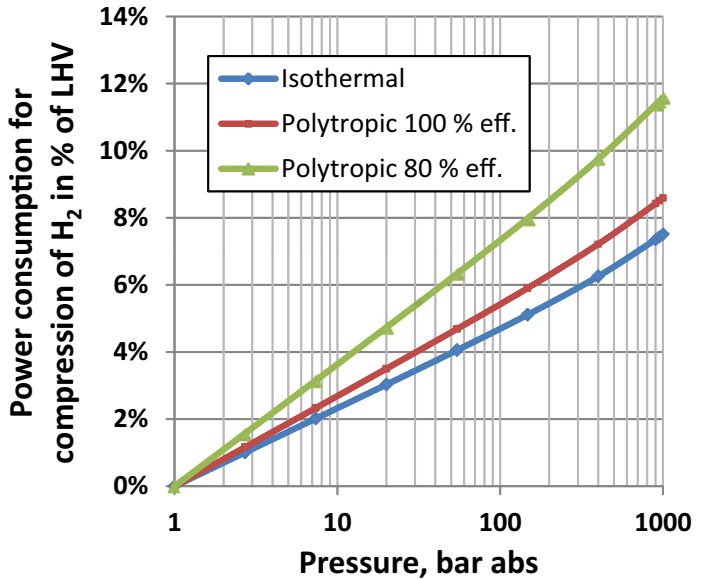

Figure 9. Calculated compression work as percentage of lower heating value of hydrogen $\left(2.997 \mathrm{kWh} \mathrm{Nm}^{-3}\right)$ for isothermal, $100 \%$ isentropic and a polytropic case with $80 \%$ effciency and $4 \%$ work loss.

very pronounced, so $42 \%$ of the compression energy needed to go to 900 bar is already expended when reaching 20 bar.

The energy consumption incurred for the balance of plant components obviously also needs to be accounted for.

Here it is instructive to examine a flowsheet for stand alone hydrogen production like (Fig. 10).

If the operating pressure is increased from 1 to 20 bar the water pumps needs to deliver a higher pressure but the power required is marginal (approx. $1 \mathrm{Wh} \mathrm{Nm}^{-3} \mathrm{H}_{2}$ ). If the low and high pressure plant are designed for the same pressure drop the power consumption of the hydrogen recycle compressor will actually be higher in the low pressure plant due to the higher compression ratio.

In Table IV the consumption numbers are summarized for the two configurations. All the consumption and production numbers are in Wh Nm${ }^{-3} \mathrm{H}_{2}$.

Economy.-In order to evaluate the investment and maintenance cost, estimations have been made for an SOEC plant operating at ambient pressure versus a plant operating at 20 bar. Both plants deliver hydrogen at 20 bar.

In the SOEC plant operating at ambient pressurre the hydrogen compressors represent a major investment and maintenance cost. They are heavy and complex machines in order to avoid contamination of
Table IV. Power consumption and district heat production numbers in Wh per $\mathrm{Nm}^{3} \mathrm{H}_{2}$.

\begin{tabular}{ccc} 
& \multicolumn{2}{c}{ SOEC operating pressure } \\
\cline { 2 - 3 } System item & 1 bar & 20 bar \\
\hline Stack & 3078 & 3079 \\
Electric superheat & 50 & 53 \\
Evaporation & 613 & 538 \\
Recycle and pumps & 15 & 6 \\
H$_{2}$ compressors & 150 & 0 \\
Sum Consumption & $\mathbf{3 9 0 6}$ & $\mathbf{3 6 7 6}$ \\
Efficiency LHV \% & 76.7 & 81.5 \\
Efficiency HHV \% & 90.7 & 96.3 \\
District heating production & 158 & 121 \\
DH effciency LHV \% & 5.3 & 4.0
\end{tabular}

the produced hydrogen. Machines compressing from 0 to 20 bar are rather uncommon and diffcicult to get reliable quotes for.

The cost estimates have therefore been based on real and projected data for compressors elevating the pressure from 20 to 400 bars. As the 20 to 400 bar steps have the same compression ratio as the compression from 1 to 20 bar it seems fair to assume an investment cost in the order of $10000-12000 € / \mathrm{kg} / \mathrm{h}$ or $1000 €$ per $\mathrm{Nm}^{3} / \mathrm{h}$ of hydrogen.

A maintenance cost of around $4 \%$ of the investment cost per year has been assumed.

Calculations of the needed heat transfer area in the heat exchangers have also been carried out for the ambient pressure as well as the 20 bar case using Haldor Topsøe A/S proprietary software for the generic SOEC based hydrogen plant. The needed heat transfer area drops by a factor of 2 if the pressure drop across the heat exchangers is kept constant. This more than compensates for the need for a thicker enclosure of the heat exchangers. In fact, the cost of the pressurized heat exchanger will be only $64 \%$ of exchangers for ambient pressure operation.

The pressure vessel enclosing the SOEC stacks has conservatively been estimated to cost around $100 € / \mathrm{Nm}^{3} / \mathrm{h}$ extra.

An SOEC hydrogen plant producing $1000 \mathrm{~kg} \mathrm{H}_{2}$ per day has been projected to cost around $925,000 €$ in 2020 for pressurized stack operation $>20$ bar provided that the stacks are mass produced in a factory having a yearly capacity above 200 MW per year. If the stacks can only operate at ambient pressure the cost will based on the above estimates increase by $40-50 \%$. Furthermore, over a 5-year period with 8000 hour operating time per year the saving in electricity of $0.23 \mathrm{kWh} / \mathrm{Nm}^{3} \mathrm{H}_{2}$ (see Table IV) amounts to

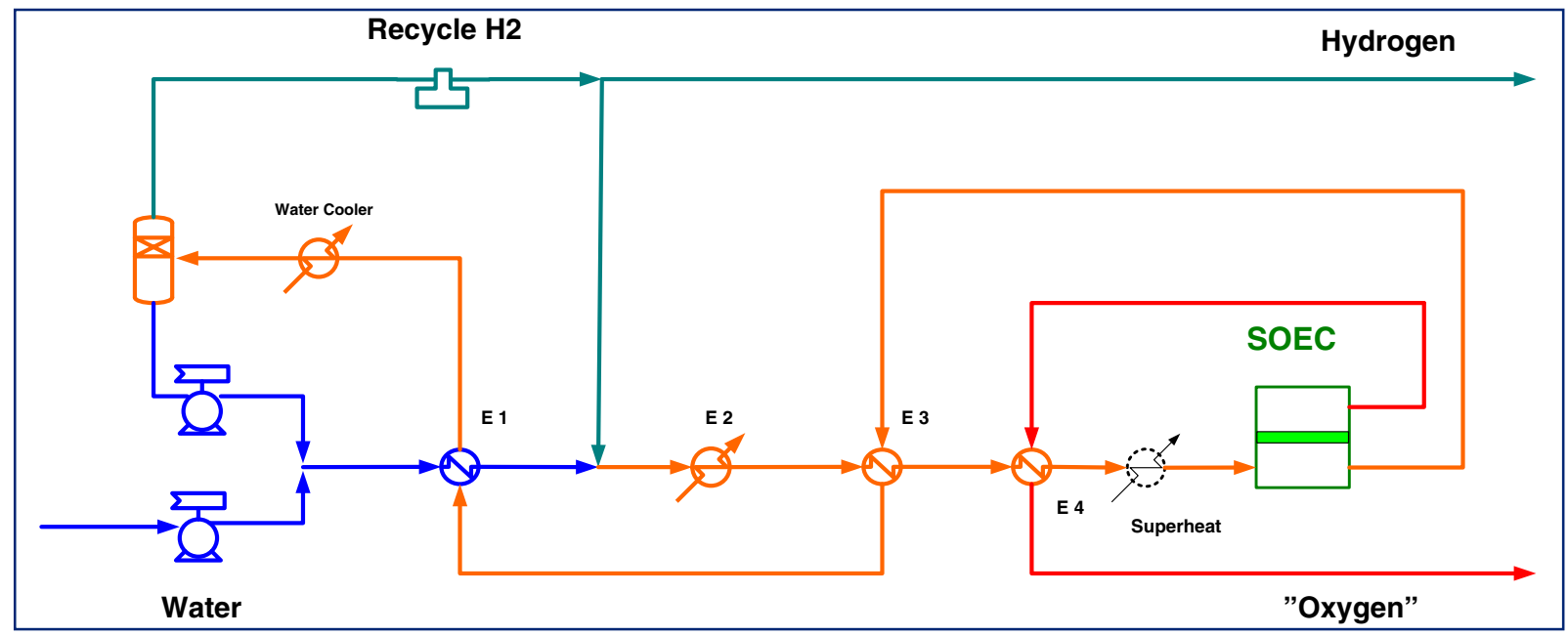

Figure 10. Generic flowsheet for a SOEC hydrogen plant. 
$128,000 €$. The saved maintenance cost of the compressors amounts to $93,000 €$

Although these estimates are rather approximate they are precise enough to indicate that there exists a strong incentive to further develop pressurized SOEC stacks and balance of plant technology.

\section{Conclusions}

A planar 11-cell solid oxide stack was characterized in both fuel cell mode and electrolysis mode at elevated pressure from 1 bar to 10 bar with various flow rates of steam and hydrogen to the $\mathrm{Ni}$-YSZ-electrodes and flow rates of air to the LSCF-CGO electrodes. A 5 hour constant current test was conducted at 10 bar to demonstrate stable pressurized electrolysis operation. The main conclusions from the stack characterization were:

- The temperature variations of the gas inside the furnace increases dramatically with pressure. This is possibly related to increased heat dissipation with pressure from the furnace to the surroundings. This highlights one of the benefits which can be achieved if the SOC stacks can be operated at $500-600^{\circ} \mathrm{C}$. At such low temperatures a hot pressure bearing housing can be placed inside the insulation material which decreases the pressurized volume and increases the efficiency of the insulation material.

- The pressure drop of the gas through the stack is seen to decrease with increasing pressure. For the measured operating conditions, the pressure drop seems to be quasi-isentropic and to follow Darcy's law.

- The measured cell OCV deviates increasingly from the Nernst voltage with increasing pressure. The reason for this is not fully understood, but since the Nernst voltage depends on the stack temperature an erroneous stack temperature measurement could possibly explain the increasing deviation.

- The ASR was seen to decrease with increasing pressure. The ASR distribution across the cells is seen to be reasonably stable with pressure indicating that the temperature variation from cell to cell within the stack is fairly independent of pressure. This means the temperature variation in the furnace at high pressure does not affect the temperature distribution inside the stack.

- Impedance recorded at various gas compositions and pressures show that the high-frequency process at $10 \mathrm{kHz}$ is affected by the steam partial pressure and that the size of the associated arc decreases with increasing pressure.

- Stack iV curves recorded at 1-10 bar tend to become increasingly linear with increasing pressure. We suggest that this is related to the increased heat exchange between the stack and the surrounding gas.

- The conversion efficiency for an SOEC based hydrogen plant including balance of plant consumptions on a lower heating value basis increases from $76.0 \%$ to $81.5 \%$ if the stack operating pressure is increased from 1 to 20 bar
- The investment cost will be $40-50 \%$ higher for a plant operating at 1 bar compared to a 20 bar plant. The savings in operating and maintenance cost amounts to $4-5 \%$.

\section{Acknowledgment}

The authors thank Haldor Topsoe A/S for supplying the tested stack. Further the authors acknowledge financial support from the Energy Technology Development and Demonstration Programme (EUDP) under the Danish Energy Agency via the project "E2P2H2" (contract no. 64013-0583) and from Energinet.dk through the ForskEL project "SOFC4RET" (contract no. 2014-1-12231). Mogens Mogensen is acknowledged for initiating the pressure test activities at DTU through the Strategic Research Center SERC, 2104-06-0011.

\section{References}

1. W. Dönitz, R. Schmidberger, E. Steinheil, and R. Streicher, Int. J. Hydrogen Energy, 5, 55 (1980)

2. A. O. Isenberg, Solid State Ionics, 3-4, 431 (1981).

3. S. D. Ebbesen, S. H. Jensen, A. Hauch, and M. B. Mogensen, Chem. Rev, 114, 10697 (2014).

4. S. D. Ebbesen, J. V. T. Høgh, K. A. Nielsen, J. U. Nielsen, and M. Mogensen, Int. J. Hydrogen Energy, 36, 7363 (2011).

5. J. Schefold, A. Brisse, and M. Zahid, ECS Trans., 28, 357 (2010).

6. M. Chen, J. V. T. Høgh, J. U. Nielsen, J. J. Bentzen, S. D. Ebbesen, and P. V. Hendriksen, Fuel Cells, 13, 638 (2013).

7. X. Zhang, J. E. O'Brien, R. C. O’Brien, J. J. Hartvigsen, G. Tao, and G. K. Housley, Int. J. Hydrogen Energy, 38, 20 (2013).

8. S. D. Ebbesen, C. Graves, A. Hauch, S. H. Jensen, and M. Mogensen, J. Electrochem. Soc., 157, B1419 (2010).

9. X. Zhang, J. E. O'Brien, and R. C. O'Brien, in ASME 2012 10th Int. Conf. on Fuel Cell Science, Eng. and Techn., p. 1, San Diego, California (2012).

10. J. B. Hansen, N. Christiansen, and J. U. Nielsen, ECS Trans., 35, 2941 (2011).

11. C. V. Olshausen and D. Rüger, in Proc. 10th European SOFC forum, p. A0506, Luzern, Switzerland (2012).

12. S. H. Jensen, X. Sun, S. D. Ebbesen, R. Knibbe, and M. Mogensen, Int. J. Hydrogen Energy, 35, 9544 (2010).

13. J. E. O'Brien, X. Zhang, G. K. Housley, K. DeWall, L. Moore-McAteer, and G. Tao, INL, Report No. 12-26891, Idaho Falls, Idaho (2012).

14. A. Momma, K. Takano, Y. Tanaka, T. Kato, and A. Yamamoto, ECS Trans., 57, 699 (2013).

15. X. Sun, A. D. Bonaccorso, C. Graves, S. D. Ebbesen, S. H. Jensen, A. Hagen, P. Holtappels, P. V. Hendriksen, and M. B. Mogensen, Fuel Cells, 15, 697 (2015).

16. L. Bernadet, G. Gousseau, A. Chatroux, J. Laurencin, F. Mauvy, and M. Reytier, Int. J. Hydrogen Energy, 40, 12918 (2015).

17. L. Bernadet, G. Gousseau, A. Chatroux, J. Laurencin, F. Mauvy, and M. Reytier, ECS Trans., 68, 3369 (2015)

18. S. H. Jensen, X. Sun, S. D. Ebbesen, and M. Chen, Fuel Cells, 2, 205 (2016).

19. R. Kikuchi, T. Yano, T. Takeguchi, and K. Eguchi, Solid State Ionics, 174, 111 (2004).

20. E. C. Thomsen, G. W. Coffey, L. R. Pederson, and O. A. Marina, J. Power Sources, 191, 217 (2009).

21. S. H. Jensen, K. Engelbrecht, and C. Bernuy-Lopez, J. Electrochem. Soc., 159, A791 (2012).

22. P. Forchheimer, Z. Ver. Dtsch. Ing., 45, 1781 (1901)

23. S. Whitaker, Transp. Porous. Med., 25, 27 (1996).

24. Z. W. Zeng and R. Grigg, Transp. Porous Media, 63, 57 (2006)

25. G. Hughes, J. Railsback, D. Butts, and S. A. Barnett, ECS Trans., 68, 687 (2015). 